\title{
First-trimester rupture of a scarred uterus after use of sublingual misoprostol: a case report
}

\author{
Ahmed M. Abbas, ${ }^{1}$ Amera M. Sheha,${ }^{2}$ Reda S. Hussein, ${ }^{1}$ Esraa Talaat, ${ }^{2}$ Mostafa Nasr \\ $\mathrm{Ali}^{1}$
}

Keywords: Uterine rupture, misoprostol, scarred uterus, maternal morbidity

\begin{abstract}
Uterine rupture is a disastrous obstetric complication, occurring mostly in the second and third trimesters. The risk of uterine rupture markedly increases with previous uterine surgeries. Termination of early pregnancy failure using misoprostol is common. However, its use in women with a scarred uterus is speculative and usually puts the obstetricians in a stressful situation. Here we present a case of rupture of a scarred uterus in the first trimester after sublingual misoprostol. A 35 years old multiparous woman presented with uterine rupture after administration of small doses of sublingual misoprostol for termination of early pregnancy failure. Immediate laparotomy was done and the defect was repaired. Termination of early pregnancy failure, in women with a scarred uterus, using sublingual misoprostol can lead to uterine rupture. Sublingual misoprostol should be used cautiously under close supervision or other routes (vaginal or oral) should be used instead.

${ }^{1}$ Department of Obstetrics and Gynecology, Faculty of Medicine; Assiut University, Assiut, Egypt
\end{abstract}

${ }^{2}$ Faculty of Medicine; Assiut University, Assiut, Egypt

\section{Introduction}

Uterine rupture is an obstetric emergency, with a high risk of maternal and fetal mortality and morbidity. ${ }^{1}$ It is rare, with an incidence that ranges from 1 in 8,000 to 1 in 15,000 pregnancies. ${ }^{2}$ It commonly occurs in the second or third trimester, especially in women with a scarred uterus. ${ }^{1,3}$ Misoprostol, a synthetic prostaglandin E1 analogue, is very effective in terminating early pregnancy failures, as it induces uterine contractions and ripens the cervix. ${ }^{4}$ Different doses and routes of administration (oral, sublingual, vaginal, or rectal) have been used. ${ }^{4}$ However, the appropriate dose and route of administration is not well-determined. ${ }^{5}$

Here, we present a case of a first

Please cite this paper as: Abbas AM, Sheha AM, Hussein RS, Talaat E, Ali MN. First-trimester rupture of a scarred uterus after use of sublingual misoprostol: a case report. Proc Obstet Gynecol. 2016;6(2): Article 5 [ 6 p.]. Available from: http://ir.uiowa.edu/pog/ Free full text article.

Corresponding author: Ahmed M. Abbas, Department of Obstetrics and Gynecology, Faculty of Medicine; Assiut University, Assiut, Egypt, bmr90@hotmail.com

Financial Disclosure: The authors report no conflict of interest.

Received: 18 May 2016; accepted 27 July 2016; POG in Press,28 July 2016

Copyright: (c) 2016 Abbas et al. This is an open-access article distributed under the terms of the Creative Commons Attribution License, which permits unrestricted use, distribution, and reproduction in any medium, provided the original author and source are credited. 
trimester ruptured uterus in a woman with a scarred uterus with a missed miscarriage, after receiving sublingual misoprostol.

\section{Case Presentation}

In March 2016, a 35-year-old woman, gravida 5 , para $3+1$, presented to the emergency unit of Assiut Women's Health Hospital, Egypt at 13 weeks of gestation (based on her last menstrual period) with an acute onset of severe lower abdominal pain experienced after receiving two doses of misoprostol (200 $\mu \mathrm{g}$ sublingually), 12 hours apart, at home for termination of missed miscarriage. She has three living children delivered by elective cesarean sections performed through transverse lower uterine segment incision, the last one three years ago. Also, she had a history of previous hysterotomy, done for missed miscarriage at 20 weeks of gestation.

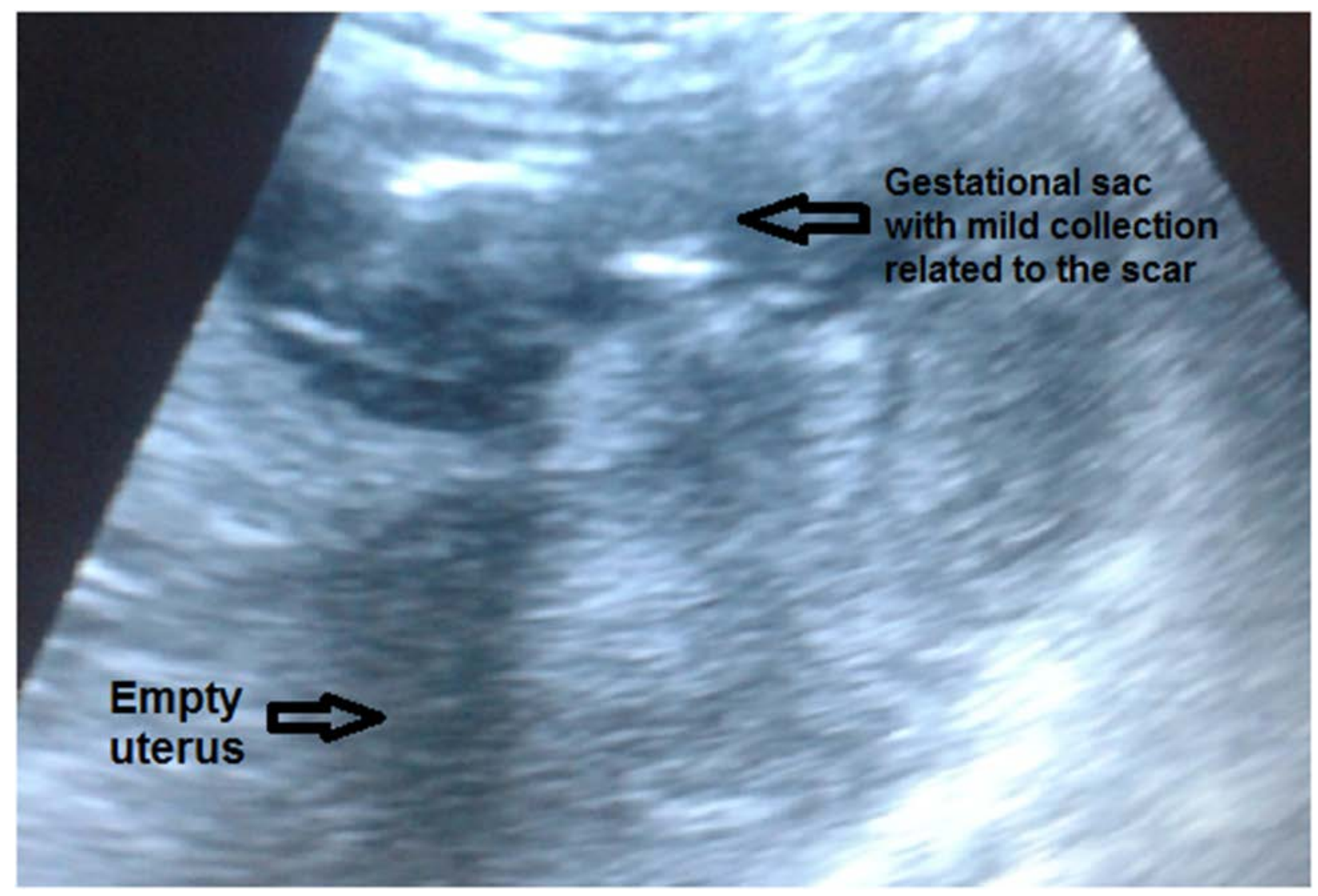

Figure 1: Abdominal ultrasound shows empty uterus, mild collection and fetus in front of the anterior uterine wall at the site of scar 
On general examination, the patient was conscious, pale, her pulse was noted to be 110 beats $/ \mathrm{min}$, blood pressure $100 / 60 \mathrm{mmHg}$, and temperature $37^{\circ} \mathrm{C}$. An abdominal examination revealed generalized tenderness and rebounding in the lower abdomen. Pelvic examination showed a closed noneffaced cervix and tender enlarged uterus. Neither adnexa was palpable. There was no vaginal discharge or bleeding. A transabdominal ultrasound scan revealed a bulky empty uterus with mild free intraperitoneal fluid collection, and a single fetus in front of the anterior uterine wall at the site of scarring, with absent cardiac activity, that measured 12.5 weeks by crown-rump length (Figure 1). The placenta was seen nonseparated attached to the anterior uterine wall. Hematological examination showed hemoglobin level $9.2 \mathrm{~g} / \mathrm{dl}$, platelet count $270,800 / \mathrm{mm}^{3}$, WBCs

\author{
$19,000 / \mathrm{mm}^{3}$ and prothrombin \\ concentration $100 \%$.
}

The patient was counseled concerning the possibility of a ruptured uterus, and informed consent for abdominal exploration with the possible need for hysterectomy was obtained. In view of the high index of suspicion for a ruptured uterus, an urgent exploratory laparotomy though a Pfannenstiel's incision was performed under general anesthesia. On opening the abdomen, free blood collection was noted with a defect in the lower uterine segment about $3 \mathrm{~cm}$ in length, and the gestational sac with the dead fetus outside the uterus (Figure 2). The fetus was removed from the abdomen and the defect was repaired in two layers by non-absorbable sutures. The abdomen was closed in layers after normal saline lavage.

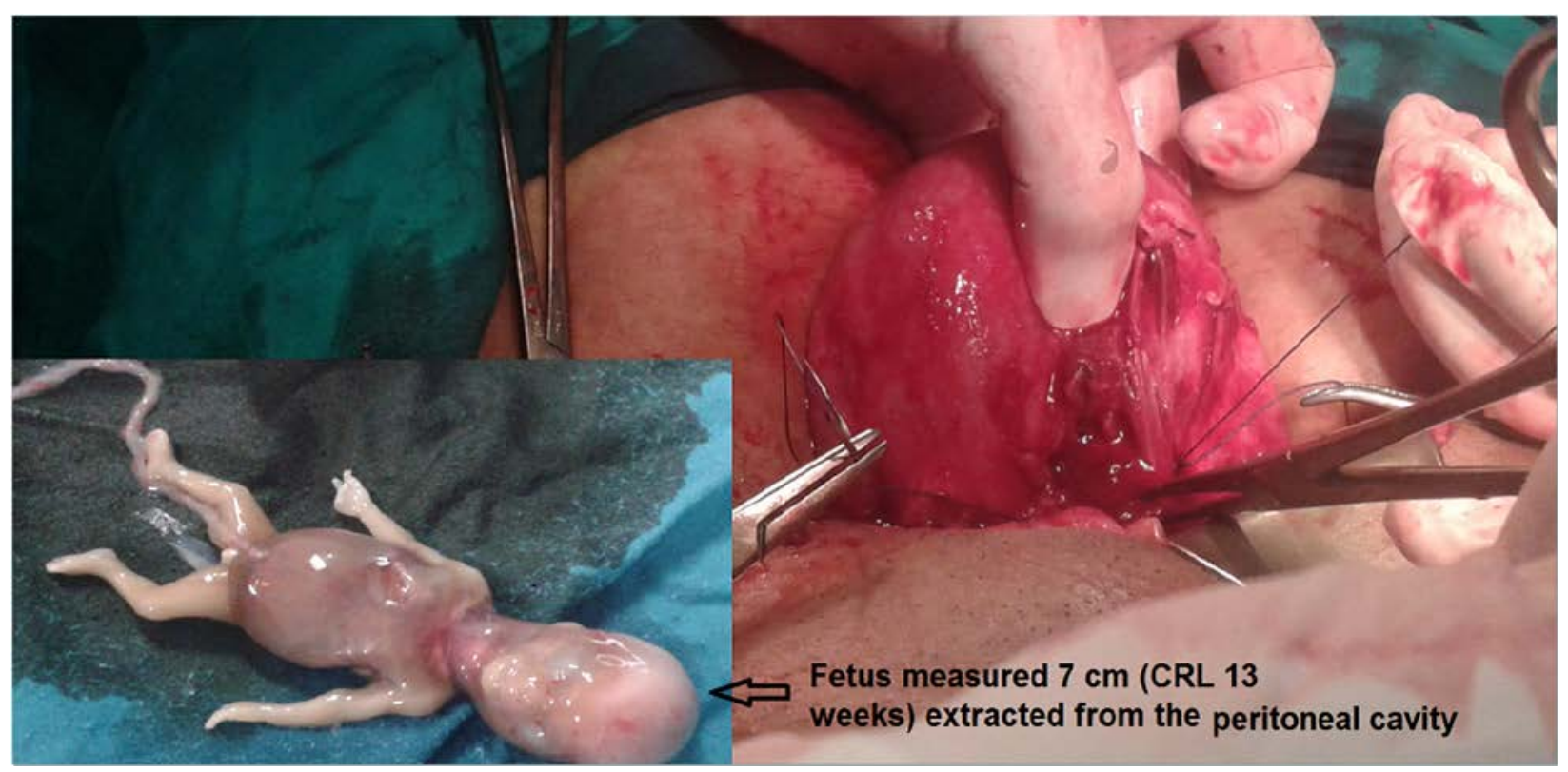

Figure 2: Uterus shows a defect in the lower uterine segment and fetus measured $7 \mathrm{~cm}$ (CRL =13 weeks) extracted from the peritoneal cavity. 
The patient received one liter of whole cross-matched blood during the operation. The operative time was 65 minutes, and the patient's estimated intraoperative blood loss was $400 \mathrm{cc}$. A urethral Foley's catheter was fixed and 2 $\mathrm{gm}$ intravenous 3rd generation cephalosporin was given. The patient had a smooth recovery from anesthesia, then she was transferred to the postoperative care room. She passed flatus seven hours after surgery, and defecated the next morning. Postoperative HB level was $10.8 \mathrm{gm} / \mathrm{dl}$. The postoperative course was uneventful and the patient was discharged on the 3rd day without complaint.

\section{Discussion}

Uterine rupture can occur following a lower segment cesarean section or upper uterine segment surgeries, including; hysterotomy, classical cesarean section, and myomectomy, which carry an increased risk of uterine rupture early during pregnancy. ${ }^{6}$ Rupture of an unscarred uterus is quite rare; however, it can occur especially in multiparous women, abnormal placentation, instrumental delivery and labor induction by misoprostol in the third trimester. ${ }^{7}$

Early pregnancy failure is common, occurring in $15-20 \%$ of known pregnancies. $^{5}$ It is a perplexing complication especially in women with previous uterine surgery. Termination of early pregnancy failure can be achieved through expectant management, surgical evacuation, or medical management. ${ }^{4}$ There is no definite protocol with evidence-based efficacy, safety and acceptability for termination of early pregnancy failure in women with a scarred uterus. This represents a great challenge to obstetricians to make a proper decision relevant to each case.

Medical management by prostaglandins is highly effective and avoids complications related to surgical evacuation. Based on the pharmacokinetics of different routes of administration, the rate of absorption and peak concentration are greatest in the sublingual route. ${ }^{8}$ This may share a greater part in increasing the risk of uterine rupture than the other routes. In our case, a previous uterine surgery and the use of misoprostol may be implicated in the uterine rupture. The point of distinction in our case is that the uterine rupture occurred after a low dose of misoprostol in the first trimester. This is contrary to the largest case series which showed that the use of misoprostol in women with prior uterine surgery is acceptable and has a similar success rate and complication rate as women without uterine surgery. ${ }^{9}$

To our knowledge, there are only two reported cases in the published literature about a uterine rupture in the first-trimester following misoprostol use, though only one of them occurred in the site of a previous cesarean section. ${ }^{10,11}$ There is also one reported case of a uterine rupture in the first trimester in the site of previous lower segment cesarean section, but without the use of oxytocics. ${ }^{12}$ The rate of uterine rupture following previous CS with vaginal misoprostol $(25-50 \mu \mathrm{gg})$ is $6.2 \%$ according to data from Ophir et $\mathrm{al}^{13}$ and Al-Zirqi et al. ${ }^{14} \mathrm{~A}$ recent 2014 Cochrane review showed no uterine rupture among 158 women with a scarred uterus after the administration of oral 
misoprostol. $^{15}$

An immediate laparotomy is the key to the successful treatment of a uterine rupture. It is recommended to use a contraceptive method for one year after the repair of uterine rupture ${ }^{16}$ and close monitoring is needed in the following pregnancies.

Known risk factors for a uterine rupture including the type of uterine scar, dose and route of administration of oxytocics would need to be taken into account when selecting patients for medical termination of early pregnancy failure. This highlights the need for further research in the context of misoprostol dosage and the route of administration in women with a scarred uterus having first trimester induction of miscarriage.

\section{Conclusion}

This case highlights the fact that uterine rupture can occur in early pregnancy when associated with a scarred uterus. Misoprostol should be used cautiously for termination of a first trimester miscarriage even in low doses for women with a scarred uterus. The obstetrician should be aware of this potentially life-threatening condition.

\section{References}

1. Turner MJ. Uterine rupture. Best Pract Res Clin Obstet Gynaecol. 2002 Feb;16(1):69-79. http://dx.doi.org/10.1053/beog.2001.025 6 PubMed PMID: 11866498.
2. Sun $H D$, Su $W H$, Chang $W H$, Wen $L$, Huang BS, Wang PH. Rupture of a pregnant unscarred uterus in an early secondary trimester: a case report and brief review. J Obstet Gynaecol Res. 2012 Feb;38(2):442-5.

http://dx.doi.org/10.1111/j.1447-

0756.2011.01723.x Epub 2012 Jan 10. PubMed PMID: 22229814.

3. Kong KY, Jang SK, Lee JY, Chung JK, Kim YJ. A clinical evaluation on the rupture of the gravid uterus. Korean $\mathrm{J}$ Obstet Gynecol. 1993 Jul;36(7):14861490. Korean

4. Ambusaidi Q, Zutshi A. Effectiveness of Misoprostol for Induction of FirstTrimester Miscarriages: Experience at a single tertiary care centre in Oman. Sultan Qaboos Univ Med J. 2015 Nov;15(4):e534-8.

http://dx.doi.org/10.18295/squmj.2015.1 5.04.016 Epub 2015 Nov 23. PubMed PMID: 26629383

5. Seervi N, Hooja N, Rajoria L, Verma A, Malviya K, Mehta N. Comparison of different regimes of misoprostol for the termination of early pregnancy failure. Med J Armed Forces India. 2014 Oct;70(4):360-3.

http://dx.doi.org/10.1016/j.mjafi.2014.08. 012 Epub 2014 Oct 8. PubMed PMID: 25382911

6. Matsuo K, Shimoya K, Shinkai T, Ohashi H, Koyama M, Yamasaki $M$, Murata $Y$. Uterine rupture of cesarean scar related to spontaneous abortion in the first trimester. J Obstet Gynaecol Res. $\quad 2004 \quad$ Feb;30(1):34-6. http://dx.doi.org/10.1111/j.13418076.2004.00152.x PubMed PMID: 14718018. 
7. Berghahn L, Christensen D, Droste S. Uterine rupture during second-trimester abortion associated with misoprostol. Obstet Gynecol. 2001 Nov;98(5 Pt 2):976-7.

http://dx.doi.org/10.1097/00006250200111001-00037 PubMed PMID: 11704229.

8. Canadian Pharmacists Association. Compendium of Pharmaceuticals and Specialties: The Canadian drug reference for health professionals. Ottawa, Canada: Canadian Pharmaceutical Association, 2005.

9. Chen BA, Reeves MF, Creinin MD, Gilles JM, Barnhart K, Westhoff C, Zhang J; National Institute of Child Health and Human Development Management of Early Pregnancy Failure Trial. Misoprostol for treatment of early pregnancy failure in women with previous uterine surgery. Am J Obstet Gynecol. 2008 Jun;198(6):626.e1-5. http://dx.doi.org/10.1016/j.ajog.2007.11. 045 Epub 2008 Feb 15. PubMed PMID: 18279821

10. Kim JO, Han JY, Choi JS, Ahn HK, Yang $\mathrm{JH}$, Kang IS, Song MJ, NavaOcampo AA. Oral misoprostol and uterine rupture in the first trimester of pregnancy: a case report. Reprod Toxicol. 2005 Nov-Dec;20(4):575-7. http://dx.doi.org/10.1016/j.reprotox.2005 .04 .014 Epub 2005 Jun 27. PubMed PMID: 15982851.

11. Jwarah E, Greenhalf JO. Rupture of the uterus after 800 micrograms misoprostol given vaginally for termination of pregnancy. BJOG. 2000 Jun;107(6):807. http://dx.doi.org/10.1111/j.14710528.2000.tb13346.x PubMed PMID: 10847241.
12. Matsuo K, Shimoya K, Shinkai T, Ohashi $H$, Koyama $M$, Yamasaki $M$, Murata Y. Uterine rupture of cesarean scar related to spontaneous abortion in the first trimester. J Obstet Gynaecol Res. $2004 \quad$ Feb;30(1):34-6. http://dx.doi.org/10.1111/j.13418076.2004.00152.x PubMed PMID: 14718018.

13. Ophir E, Odeh M, Hirsch Y, Bornstein J. Uterine rupture during trial of labor: controversy of induction's methods. Obstet Gynecol Surv. 2012 Nov;67(11):734-45. http://dx.doi.org/10.1097/OGX.0b013e3 18273feeb PubMed PMID: 23151757.

14. Al-Zirqi I, Stray-Pedersen B, Forsén L, Vangen $S$. Uterine rupture after previous caesarean section. BJOG. 2010 Jun;117(7):809-20. http://dx.doi.org/10.1111/j.14710528.2010.02533.x Epub 2010 Mar 24. Erratum in: BJOG. 2010 Jul;117(8):1041. PubMed PMID: 20236103.

15. Alfirevic Z, Aflaifel N, Weeks A. Oral misoprostol for induction of labour. Cochrane Database Syst Rev. 2014 Jun 13;(6):CD001338.

http://dx.doi.org/10.1002/14651858.CD0 01338.pub3 PubMed PMID: 24924489.

16. Singh N, Singh U, Verma ML. Ruptured bicornuate uterus mimicking ectopic pregnancy: A case report. J Obstet Gynaecol Res. 2013 Jan;39(1):364-6. http://dx.doi.org/10.1111/j.14470756.2012.01914.x Epub 2012 Jun 13. PubMed PMID: 22691311. 